\title{
Preoperative intravenous dexamethasone prevents tracheal intubation-related sore throat in adult surgical patients: a systematic review and meta-analysis \\ La dexaméthasone intraveineuse préopératoire évite le mal de gorge dû à l'intubation trachéale chez des patients chirurgicaux adultes : revue systématique de la littérature et méta-analyse
}

\author{
Akira Kuriyama, MD, MPH (i) - Hirokazu Maeda, MD \\ Received: 18 July 2018/Revised: 4 September 2018/ Accepted: 10 October 2018/Published online: 7 January 2019 \\ (C) Canadian Anesthesiologists' Society 2019
}

\begin{abstract}
Background Postoperative sore throat related to tracheal intubation negatively affects patient recovery and satisfaction. Previous reviews suggested that intravenous dexamethasone diminishes postoperative sore throat. Nevertheless, they comprised a small number of studies with inconsistencies in outcome reporting. We performed a systematic review and meta-analysis to assess the efficacy and safety of preoperative intravenous dexamethasone in preventing postoperative sore throat in adult patients.

Methods We searched PubMed, EMBASE, and the Cochrane Central Register of Controlled Trials from inception to August 24, 2018. We included randomizedcontrolled trials that assessed the efficacy and safety of intravenous dexamethasone in adult surgical patients who required general anesthesia and endotracheal intubation. Our primary outcomes were the incidence and severity of sore throat at $24 \mathrm{hr}$ after surgery/extubation and adverse events. We pooled the data using a random-effects model. We conducted a trial sequential analysis (TSA) on the incidence of sore throat.
\end{abstract}

Electronic supplementary material The online version of this article (https://doi.org/10.1007/s12630-018-01288-2) contains supplementary material, which is available to authorized users.

\footnotetext{
A. Kuriyama, MD, MPH ( $\square)$

Emergency and Critical Care Center, Kurashiki Central Hospital, 1-1-1 Miwa Kurashiki, Okayama 710-8602, Japan

e-mail: akira.kuriyama.jpn@gmail.com

H. Maeda, MD

Department of Emergency Medicine, Sugita Genpaku Memorial

Obama Municipal Hospital, Fukui, Japan
}

Results We included 15 randomized-controlled trials involving 1,849 patients. In comparison with nonanalgesic methods, intravenous dexamethasone was associated with a reduced incidence (risk ratio, 0.62; $95 \%$ confidence interval [CI], 0.51 to 0.75$)$ and severity (standardized mean difference, - 1.06; 95\% CI, - 1.80 to - 0.33) of postoperative sore throat. Serious adverse events were not associated with intravenous dexamethasone administration in the four studies where this was assessed. The TSA indicated that the evidence regarding the incidence of postoperative sore throat is adequate.

Conclusions Our study indicates that preoperative intravenous administration of dexamethasone alleviates postoperative sore throat more effectively than nonanalgesic methods.

Trial registration PROSPERO (CRD42018086697); registered 29 January, 2018.
Résumé
Contexte Le mal de gorge postopératoire lié à l'intubation trachéale a une répercussion négative sur la récupération et la satisfaction des patients. Des synthèses antérieures ont suggéré que la dexaméthasone intraveineuse diminue le mal de gorge postopératoire. Néanmoins, elles n'incluaient qu'un petit nombre d'études avec des incohérences dans la présentation des résultats. Nous avons réalisé une revue systématique de la littérature et une méta-analyse pour évaluer l'efficacité et l'innocuité de la dexaméthasone intraveineuse préopératoire pour prévenir le mal de gorge postopératoire chez des patients adultes. 
Méthodes Nous avons recherché les essais contrôlés pertinents dans PubMed, EMBASE et le Cochrane Central Register depuis leur création jusqu'au 24 août 2018. Nous avons inclus les essais contrôlés randomisés ayant évalué l'efficacité et l'innocuité de la dexaméthasone intraveineuse chez des patients chirurgicaux adultes ayant nécessité une anesthésie générale et une intubation endotrachéale. Nos principaux critères d'évaluation étaient l'incidence et la sévérité du mal de gorge 24 heures après la chirurgielextubation et les événements indésirables. Nous avons regroupé les données en utilisant un modèle à effets aléatoires. Nous avons mené une analyse séquentielle des essais sur l'incidence du mal de gorge.

Résultats Nous avons inclus 15 essais contrôlés randomisés ayant réuni 1849 patients. Comparativement aux méthodes sans analgésiques, la dexaméthasone a été associée à une diminution de l'incidence (rapport de risque, 0,62; intervalle de confiance [IC] à $95 \%: 0,51$ à 0,75 ) et de la sévérité (différence des moyennes standardisées : -1,06; IC à $95 \%,-1,80$ à -0,33) du mal de gorge postopératoire. Aucun événement indésirable grave n'a été associé à l'administration intraveineuse de dexaméthasone dans les quatre études où ils ont été évalués. L'analyse séquentielle des essais a indiqué que la preuve concernant l'incidence du mal de gorge postopératoire est adéquate.

Conclusions Notre étude indique que l'administration intraveineuse préopératoire de dexaméthasone soulage plus efficacement le mal de gorge postopératoire que les méthodes sans analgésiques.

\section{Enregistrement de l'essai clinique PROSPERO} (CRD42018086697); enregistré 29 janvier 2018.

Postoperative sore throat is common in patients who have undergone surgery under general anesthesia/endotracheal intubation, with a reported incidence of up to $68 \% .^{1-7}$ It negatively affects patient recovery and satisfaction, ${ }^{4,7-10}$ and considerable efforts have been undertaken to understand and treat this phenomenon. Mucosal trauma, erosion, and inflammation due to endotracheal intubation are proposed etiologies. ${ }^{11-15}$ Randomized-controlled trials have suggested that inhaled ${ }^{16}$ or topical ${ }^{17}$ corticosteroids, topical benzydamine hydrochloride, ${ }^{18}$ and topical licorice may help to prevent postoperative sore throat. Intravenous dexamethasone administration has also been proposed as a prophylactic measure. Two systematic reviews, based on data available in $20^{13,19,20}$ suggested that preoperative intravenous dexamethasone helps to prevent postoperative sore throat. Nevertheless, those reviews comprised a limited number of studies and the outcomes could not be appropriately pooled because the reporting methods used by the original studies were inconsistent.

Since those reviews, further studies have assessed the effect of dexamethasone treatment on postoperative sore throat and these are better suited for pooling of their findings. Therefore, we performed a systematic review and meta-analysis of the efficacy and safety of preoperative intravenous dexamethasone administration to prevent postoperative sore throat in adults subjected to tracheal intubation for general anesthesia. We focused on the incidence and severity of postoperative sore throat, and reported adverse events and postoperative cough and hoarseness.

\section{Methods}

We adhered to the Cochrane Collaboration methodology ${ }^{21}$ and PRISMA statement ${ }^{22}$ for the conduct and reporting of this systematic review. Our protocol is registered at PROSPERO (CRD42018086697).

\section{Eligibility criteria}

\section{Type of studies}

We included randomized-controlled studies that compared preoperative intravenous dexamethasone with nonanalgesic or active control treatment in adults who underwent elective surgery under general anesthesia. We excluded observational studies and quasi-randomized and non-randomized controlled trials.

\section{Type of participants}

We included adult patients aged $\geq 18 \mathrm{yr}$ who underwent elective surgery under general anesthesia and endotracheal intubation. We excluded patients whose general anesthesia care included a supraglottic airway device or those who underwent head and neck surgery that might induce confounding pain in the laryngopharynx.

\section{Type of interventions}

The intervention included dexamethasone that was intravenously administered to prevent sore throat or postoperative pain elsewhere. We placed no restrictions on the dose or the number of doses of dexamethasone, as long as it was administered preoperatively. We excluded studies that administered dexamethasone postoperatively.

Comparators included non-analgesic methods or active controls that were administered preoperatively. Non- 
analgesic strategies included no endotracheal tube lubrication, usual care, or the use of drugs without known analgesic potency, such as intravenous saline. Active controls involved agents that have known prophylactic effects against postoperative sore throat, such as topical ketamine or an analgesic combined with intravenous dexamethasone. We placed no restrictions on the dose or the number of doses of the comparators. We excluded studies that administered non-analgesic methods or active controls postoperatively.

\section{Types of outcome measures}

Our primary outcomes included 1) the incidence and 2) severity of postoperative sore throat at $24 \mathrm{hr}$ after surgery/ extubation and 3) adverse events. Because there is no established definition for postoperative sore throat, we accepted the investigators' definitions. Studies on postoperative sore throat frequently use a four-level classification system: none, mild, moderate, and severe. When a study used this classification system, we calculated the incidence of sore throat from the sum of mild, moderate, and severe cases. We accepted each study author's definition of adverse events.

Our secondary outcomes included 1) the incidence of moderate or severe sore throat, 2) cough, and 3) hoarseness at $24 \mathrm{hr}$ after surgery/extubation. Since there are no established universal definitions for postoperative cough or hoarseness, we accepted the investigators' definitions. We calculated the incidence of cough or hoarseness based on the sum of mild, moderate, and severe cases, according to the commonly-used classification system.

\section{Search strategy}

We searched PubMed, EMBASE, and the Cochrane Central Register of Controlled Trials for eligible studies. We reviewed the reference lists of the included publications and previous systematic reviews, and searched Google Scholar and ClinicaTrials.gov to identify further eligible studies. We did not search the grey literature. We placed no restrictions on publication status or language. Our search strategy is presented in Table 1. We updated the search on May 3, 2018.

Study selection

Two authors (A.K. and H.M.) independently, and in duplicate, reviewed the articles retrieved through the search and selected the eligible ones. We resolved disagreements by consensus $(\kappa=0.92)$.
Table 1 Search strategy

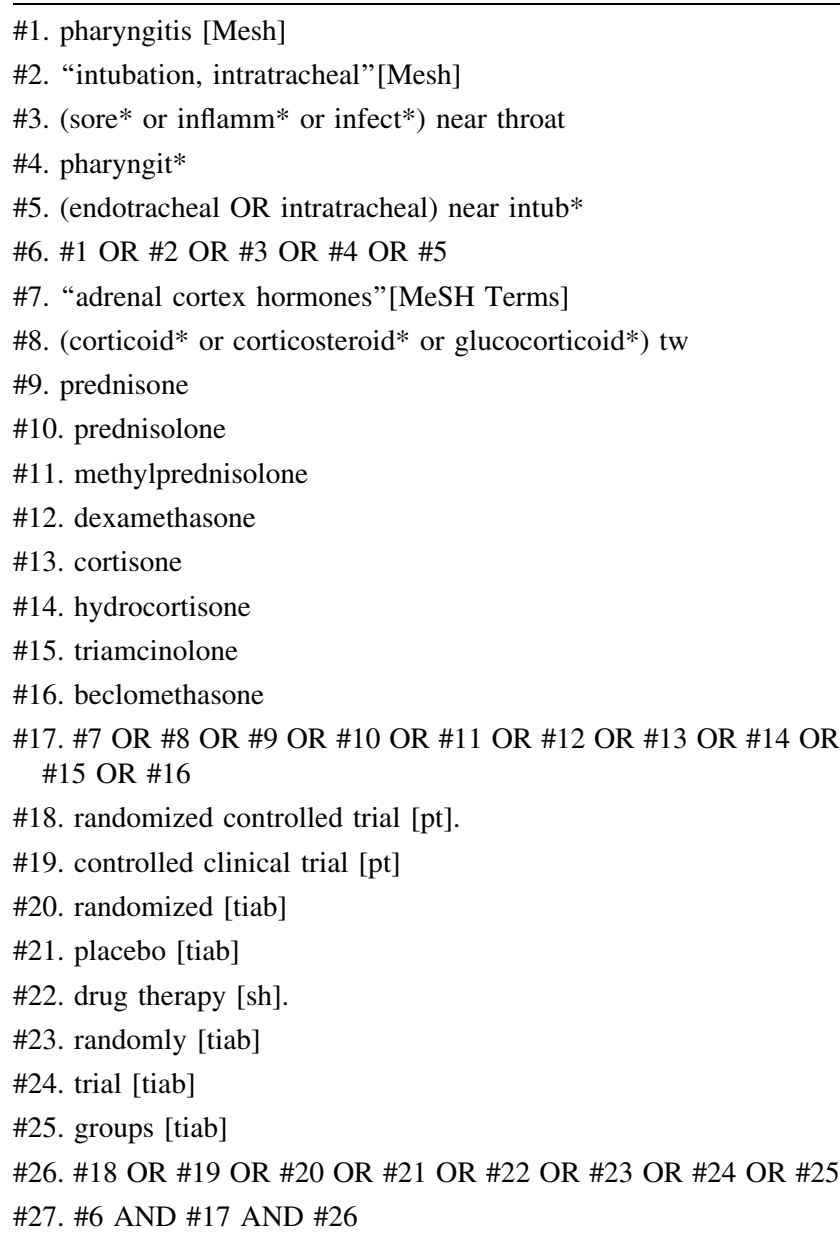

Data extraction

These two authors then independently extracted the following data from each study: patient characteristics (age, sex, and American Society of Anesthesiologists [ASA] physical status), study characteristics (country and type of surgery), interventions used (dexamethasone dose, if reported, and comparators), and outcomes of interest.

Risk of bias assessment

The same authors independently and in duplicate evaluated the risk of bias with the Cochrane risk of bias assessment tool. ${ }^{21}$ We considered a study to be at a low risk of performance bias when the original study blinded participants to the intervention they received until all assessments were complete, given that sore throat is a subjective outcome. We also reviewed for conflicts of interest or industry sponsorship. We resolved any inconsistency through discussion $(\kappa=0.53-1.0)$. When an e-mail address was available, we contacted the authors 
of the original study for more information. Specifically, we attempted to retrieve information regarding the methodology of each trial and the outcomes of interest that were not presented in the articles. We deemed the authors to be unresponsive if they did not reply after three contact attempts.

\section{Statistical analysis}

We calculated the risk ratio (RR) and standardized mean difference (SMD) for dichotomous and continuous outcomes, respectively. When a trial had zero events in either arm, we applied continuity corrections by adding 0.5 to each cell of the $2 \times 2$ tables from the trial. ${ }^{23}$ When a study presented the data as the median with interquartile range, we converted the values to the mean and standard deviation using the method proposed by Wan et al. ${ }^{24} \mathrm{We}$ pooled the data using the DerSimonian and Laird randomeffects model. ${ }^{25} \mathrm{We}$ assessed statistical heterogeneity using $Q$ and $I^{2}$ statistics. $^{26}$ We deemed $I^{2} \geq 50 \%$ as substantial statistical heterogeneity and conducted subgroup analysis by the type of non-analgesic method. Since there is no evidence to suggest that non-analgesic methods work similarly, we conducted subgroup analysis by the type of comparator. We anticipated that there would be no difference in effect size between the subgroups by the type of comparator. Because the number of studies for each outcome was less than ten, we did not test for publication bias. $^{21}$

We performed primary analyses by the type of comparator. We pooled the data into a single arm when a study examined groups based on different dexamethasone doses. We conducted sensitivity analyses by excluding trials at an unclear or high risk of bias with regard to sequence generation, allocation concealment, blinding of participants and outcome assessors, and conflicts of interest/industry sponsorship. We also conducted another sensitivity analysis by presenting the pooled outcomes of risk difference.

We conducted subgroup analysis and meta-regression to estimate the dose-response relationship for the incidence of postoperative sore throat, which had been a priori planned in case the number of studies was sufficient and a variety of regimens were used. Unless the mean body weight for the dexamethasone group was reported, we converted the dexamethasone dose to the equivalent value in $\mathrm{mg} \cdot \mathrm{kg}^{-1}$ based on the assumption that the mean body weight was 60 $\mathrm{kg}$ (most eligible studies were conducted outside North America and reported approximately $60 \mathrm{~kg}$ as the mean body weight of participants). We conducted subgroup analysis according to the following dexamethasone doses: low dose $\left(0.1 \mathrm{mg} \cdot \mathrm{kg}^{-1}\right)$ and intermediate dose $(0.11-0.20$ $\left.\mathrm{mg} \cdot \mathrm{kg}^{-1}\right){ }^{27}$ We anticipated that the preventive effect of the intermediate dexamethasone dose might be larger than that of the lower dexamethasone dose.

To evaluate our findings' robustness against type 1 and type 2 errors, we conducted trial sequential analysis (TSA) with the O'Brien-Fleming alpha-spending function method. ${ }^{28,29}$ We retained a $5 \%$ risk of type 1 errors and a power of $80 \%$. Furthermore, we obtained the required information size according to relative risk reduction of $20 \%$ for postoperative sore throat, which is the most conservative value used for the power calculations employed in the included trials. ${ }^{30}$ The threshold for statistical significance was set at $P<0.05$. We used Stata SE, version 15.1 (StataCorp., College Station, TX, USA) to perform conventional meta-analyses, while we used the TSA software, version 0.9 beta (Copenhagen Trial Unit, Copenhagen, Denmark) to conduct the TSA.

\section{Results}

Overview of included studies

Our database search initially produced 1,892 titles and abstracts, and an additional search found five articles. We ultimately included 15 randomized-controlled trials involving 1,849 study participants for the analysis after applying our inclusion and exclusion criteria ${ }^{30-44}$ (Fig. 1).

The mean age for the study participants ranged from 28 $62 \mathrm{yr}$, and the proportion of females ranged from 16\%$100 \%$ (Table 2). Twelve and three trials included patients with an ASA status of I-II and III, respectively. Eight trials listed the types of surgery as follows ${ }^{30,32-35,38-40,42,43}$ : breast and abdominal surgery (including laparoscopic cholecystectomy), orthopedic surgery (including the limbs and spine), gynecologic surgery, middle ear surgery, and thoracic surgery (open pulmonary resection or video-assisted thoracoscopic surgery). The median sample size was 110 (range, 49-226).

Intravenous dexamethasone was administered as a single-dose infusion prior to surgery in all studies. The dose was fixed in eight studies (4 mg in one study ${ }^{36} ; 8 \mathrm{mg}$ in five studies, ${ }^{32,36,39,42,44}$ and $10 \mathrm{mg}$ in three studies ${ }^{34,40,41}$ ) and was determined according to patient's body weight in five studies $\left(0.05 \mathrm{mg} \cdot \mathrm{kg}^{-1}\right.$ in one study ${ }^{33}$; $0.1 \mathrm{mg} \cdot \mathrm{kg}^{-1}$ in three studies, ${ }^{30,33,35}$ and $0.2 \mathrm{mg} \cdot \mathrm{kg}^{-1}$ in five studies). ${ }^{30,31,35,37,43}$ The remaining study did not specify the dose. Intravenous saline was used as a non-analgesic control in 12 studies. Comparator agents with known analgesic effects included betamethasone ${ }^{38}$ and triamcinolone gel $^{41}$ and were applied over endotracheal tubes (one study each); ketamine gargles ${ }^{37,43}$ or ketamine gargles combined with intravenous dexamethasone ${ }^{37,43}$ (two studies); and intravenous lidocaine ${ }^{32}$ or 


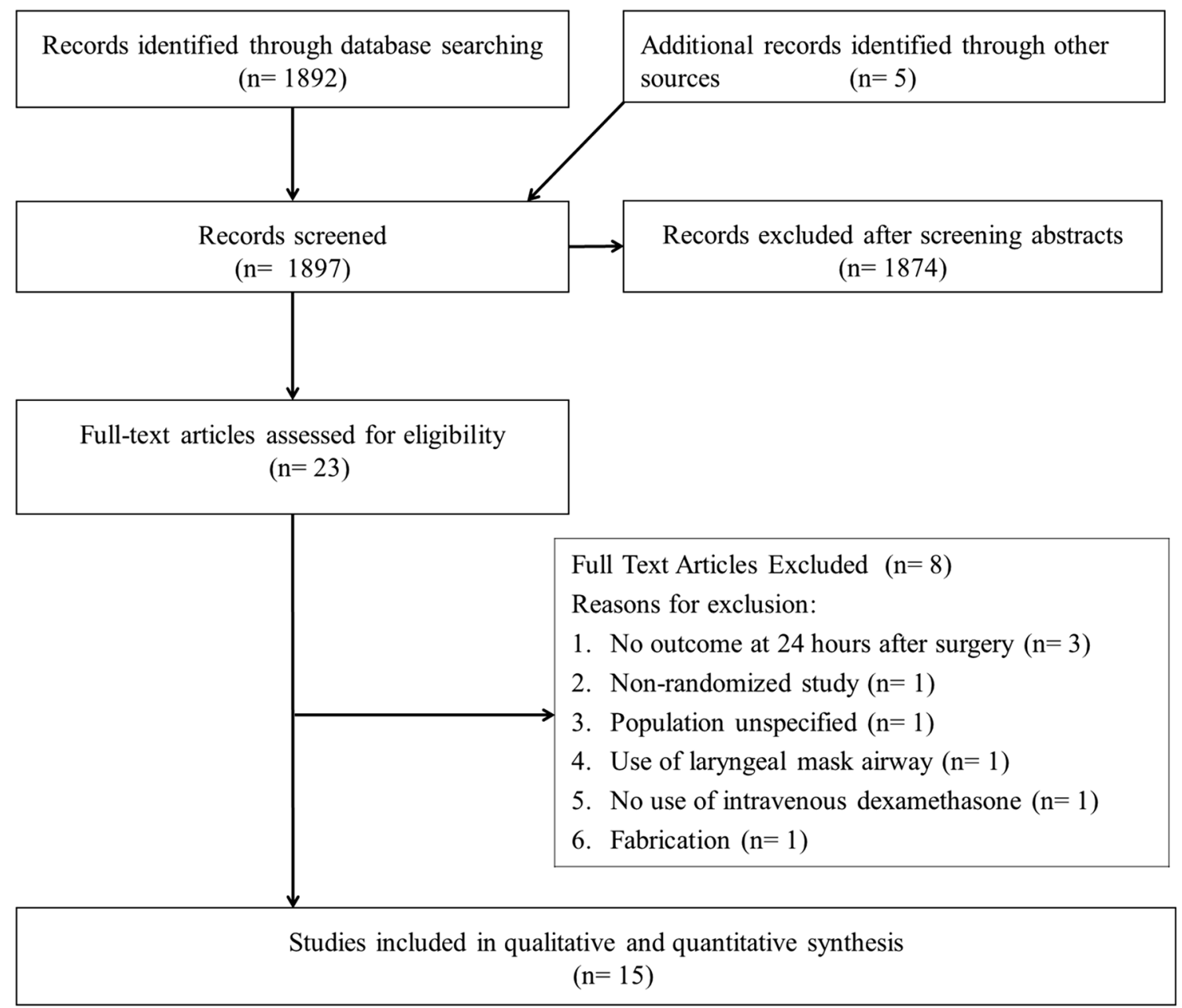

Fig. 1 Flow diagram illustrating the literature screening process and selection of studies

acetaminophen $^{34}$ combined with intravenous dexamethasone (one study each). Four trials were performed in South Korea, ${ }^{30,32,34,35}$ three in India, ${ }^{31,39,43}$ two each in $\operatorname{Iran}^{37,38}$ and Thailand, ${ }^{36,42}$ and one each in China, ${ }^{40}$ Indonesia, ${ }^{41} \mathrm{Nepal}^{44}$ and the United States of America. ${ }^{33}$ All studies were published as full text between 2007 and 2018. All studies but two were reported in English, with the remaining ones published in Chinese ${ }^{40}$ and Indonesian. ${ }^{41}$

Eight studies used a four-level classification system to rate the severity of postoperative sore throat and confirm its presence. $^{30,31,34,37,40,41,43,44}$ Two studies used a visual analog scale ${ }^{35,39}$ while two used a numeric rating scale to rate the severity. ${ }^{33,42}$ Five studies reported the incidence of postoperative sore throat. ${ }^{30,32,35,36,38}$ We contacted 11 study authors with a valid e-mail address for further information, and six responded. ${ }^{31,32,34,36,41,44}$ Most studies were at relatively low risk of bias, as shown in Table 3. Nevertheless, in one study, the duration of patient intubation in the dexamethasone group was significantly longer compared with the control group (142 vs 121 min). ${ }^{42}$ As duration of intubation is a known risk factor for postoperative sore throat, ${ }^{8}$ we considered this study to have a high risk of bias.

Dexamethasone vs non-analgesic controls

\section{Incidence of postoperative sore throat}

Nine studies comprising 983 participants provided data on the incidence of sore throat at $24 \mathrm{hr}$ after surgery/ extubation. $^{30,31,35-38,40,43,44}$ Intravenous administration of dexamethasone was associated with a lower incidence of postoperative sore throat (RR, $0.62 ; 95 \% \mathrm{CI}, 0.51$ to $0.75 ; P$ $<0.001 ;$ df $=7 ; I^{2}=0 \%$; Fig. 2).

\section{Severity of postoperative sore throat}

Four studies including 431 participants provided data on the severity of sore throat at $24 \mathrm{hr}$ after surgery/ extubation. $^{33,35,39,42}$ Intravenous administration of dexamethasone was associated with a lower severity of 


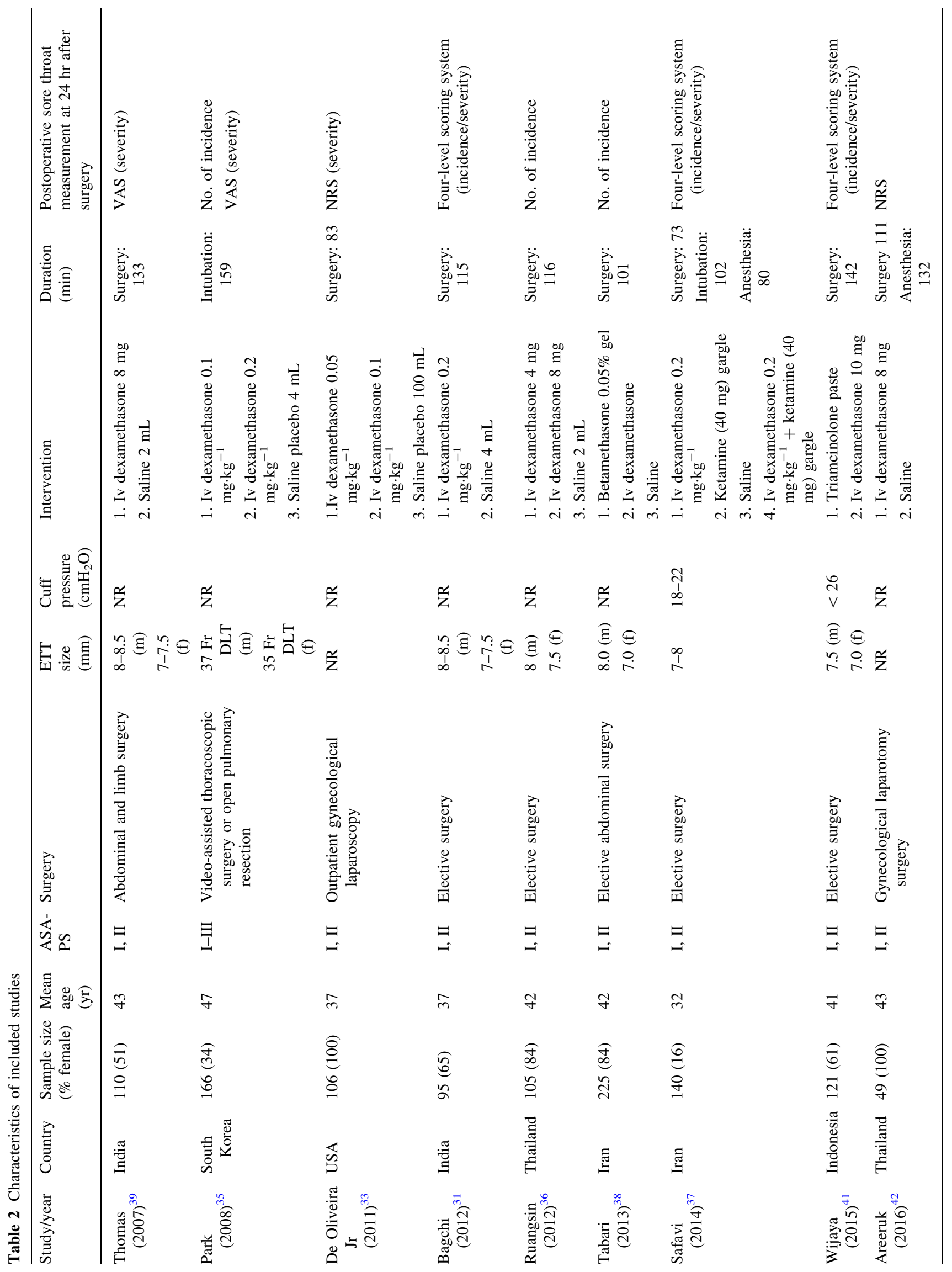




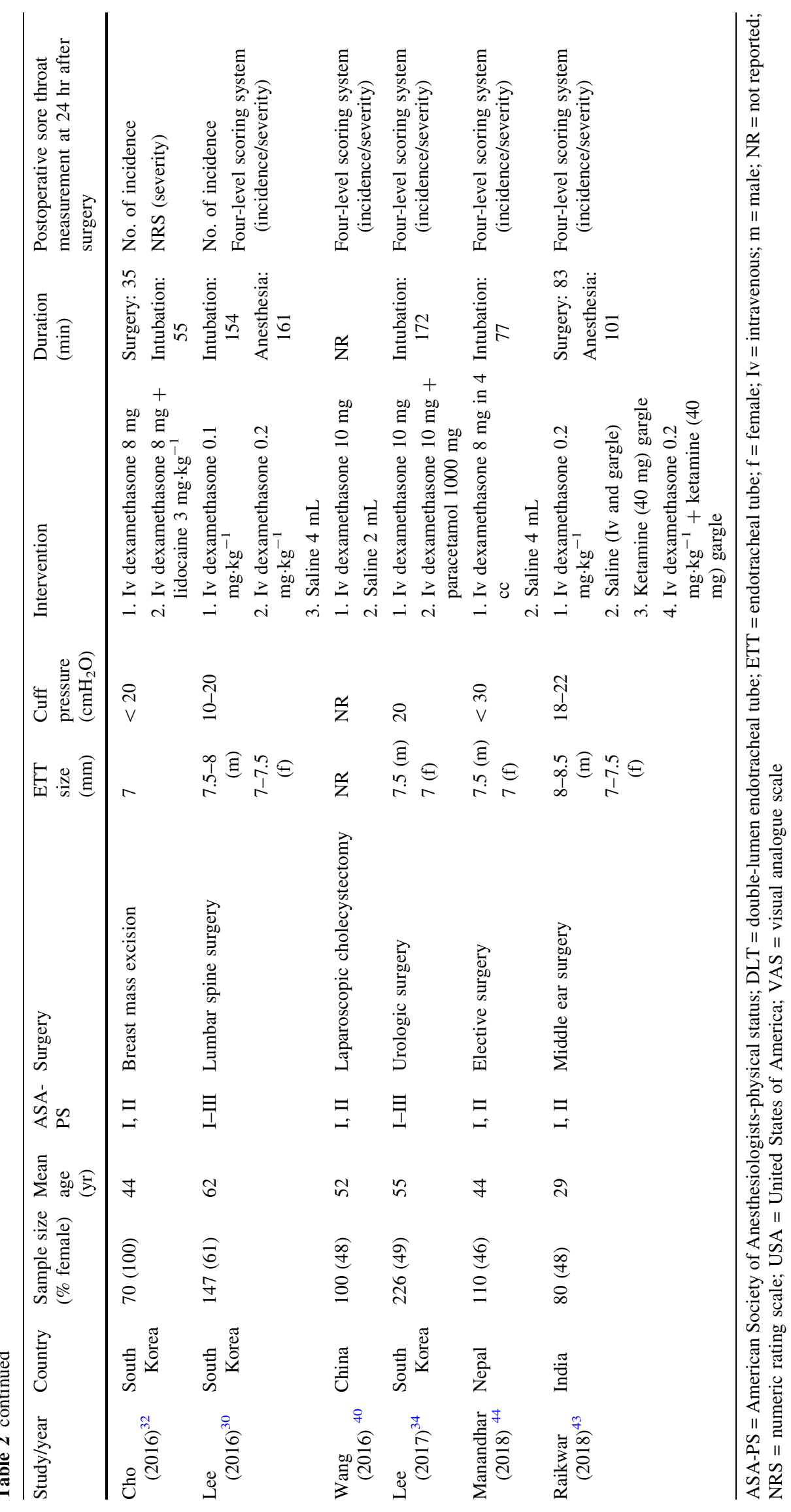


Table 3 Risk of bias in included studies

\begin{tabular}{|c|c|c|c|c|c|c|c|c|}
\hline Study & $\begin{array}{l}\text { Sequence } \\
\text { generation }\end{array}$ & $\begin{array}{l}\text { Allocation } \\
\text { concealment }\end{array}$ & $\begin{array}{l}\text { Blinding of } \\
\text { participants and } \\
\text { personnel }\end{array}$ & $\begin{array}{l}\text { Blinding of } \\
\text { outcome } \\
\text { assessors }\end{array}$ & $\begin{array}{l}\text { Incomplete } \\
\text { outcome } \\
\text { data }\end{array}$ & $\begin{array}{l}\text { Selective } \\
\text { outcome } \\
\text { reporting }\end{array}$ & $\begin{array}{l}\text { Other } \\
\text { source of } \\
\text { bias }\end{array}$ & $\begin{array}{l}\text { Industry } \\
\text { sponsorship/conflict } \\
\text { of interest }\end{array}$ \\
\hline $\begin{array}{l}\text { Thomas } \\
(2007)^{39}\end{array}$ & Low & Low & Low & Low & Low & Low & Low & Unclear \\
\hline $\begin{array}{l}\text { Park } \\
\qquad(2008)^{35}\end{array}$ & Low & Low & Low & Low & Low & Low & Low & None \\
\hline $\begin{array}{l}\text { De Oliveira } \\
\text { Jr } \\
(2011)^{33}\end{array}$ & Low & Low & Low & Low & Low & Low & Low & None \\
\hline $\begin{array}{l}\text { Bagchi } \\
\qquad(2012)^{31}\end{array}$ & Low & Low & Low & Low & Low & Low & Low & Unclear \\
\hline $\begin{array}{l}\text { Ruangsin } \\
\qquad(2012)^{36}\end{array}$ & Low & Unclear & Low & Low & Low & Low & Low & None \\
\hline $\begin{array}{l}\text { Tabari } \\
\qquad(2013)^{38}\end{array}$ & Unclear & Unclear & Low & Low & Low & Low & Low & Unclear \\
\hline $\begin{array}{l}\text { Safavi } \\
\qquad(2014)^{37}\end{array}$ & Low & Unclear & Low & Low & Low & Low & Low & Unclear \\
\hline $\begin{array}{l}\text { Wijaya } \\
\qquad(2015)^{41}\end{array}$ & Low & Unclear & Low & Low & Low & Low & Low & Unclear \\
\hline $\begin{array}{l}\text { Areeruk } \\
\qquad(2016)^{42}\end{array}$ & Low & Low & Low & Low & Low & Low & High & Unclear \\
\hline $\begin{array}{l}\text { Cho } \\
\qquad(2016)^{32}\end{array}$ & Low & Low & Low & Low & Low & Low & Low & Unclear \\
\hline $\begin{array}{l}\text { Lee } \\
\qquad(2016)^{30}\end{array}$ & Low & Low & Unclear & Low & Low & Low & Low & None \\
\hline $\begin{array}{l}\text { Wang } \\
\qquad(2016)^{40}\end{array}$ & Unclear & Unclear & Unclear & Unclear & Low & Low & Low & Unclear \\
\hline $\begin{array}{l}\text { Lee } \\
\qquad(2017)^{34}\end{array}$ & Low & Low & Low & Low & Low & Low & Low & None \\
\hline $\begin{array}{l}\text { Manandhar } \\
(2018)^{44}\end{array}$ & Low & Low & Low & Low & Low & Low & Low & Unclear \\
\hline $\begin{array}{l}\text { Raikwar } \\
\qquad(2018)^{43}\end{array}$ & Low & Low & Low & Low & Low & Low & Low & None \\
\hline
\end{tabular}

postoperative sore throat (SMD, $-1.06 ; 95 \% \mathrm{CI},-1.80$ to $-0.33 ; P=0.005 ; \mathrm{df}=3 ; I^{2}=91 \%$; Fig. 3 ).

\section{Adverse events}

Four studies reported on adverse events. One study reported that the frequency of adverse events during 24 hr after surgery was comparable between the dexamethasone and control groups, ${ }^{39}$ another noted that no adverse event was associated with dexamethasone,${ }^{35}$ the third reported that there were no differences in the incidence of local or systemic side effects between the dexamethasone and control groups, ${ }^{37}$ and the fourth reported that there were no local or systemic adverse events, except one episode of vomiting in the non-analgesic control group. ${ }^{43}$
Secondary outcomes

Moderate and severe postoperative sore throat

Six studies involving 562 participants provided data on the incidence of moderate or severe sore throat at $24 \mathrm{hr}$ after surgery/extubation..$^{30,31,36,40,43,44}$ Intravenous administration of dexamethasone was associated with a lower incidence of moderate or severe postoperative sore throat $(\mathrm{RR}, 0.10 ; 95 \% \mathrm{CI}, 0.03$ to $0.39 ; P=0.001 ; \mathrm{df}=$ $4 ; I^{2}=0 \%$; Fig. 4).

\section{Postoperative cough}

Three studies comprising 349 participants provided data on the incidence of cough at $24 \mathrm{hr}$ after surgery/ extubation. ${ }^{30,31,33}$ Intravenous administration of dexamethasone was associated with a reduced incidence 


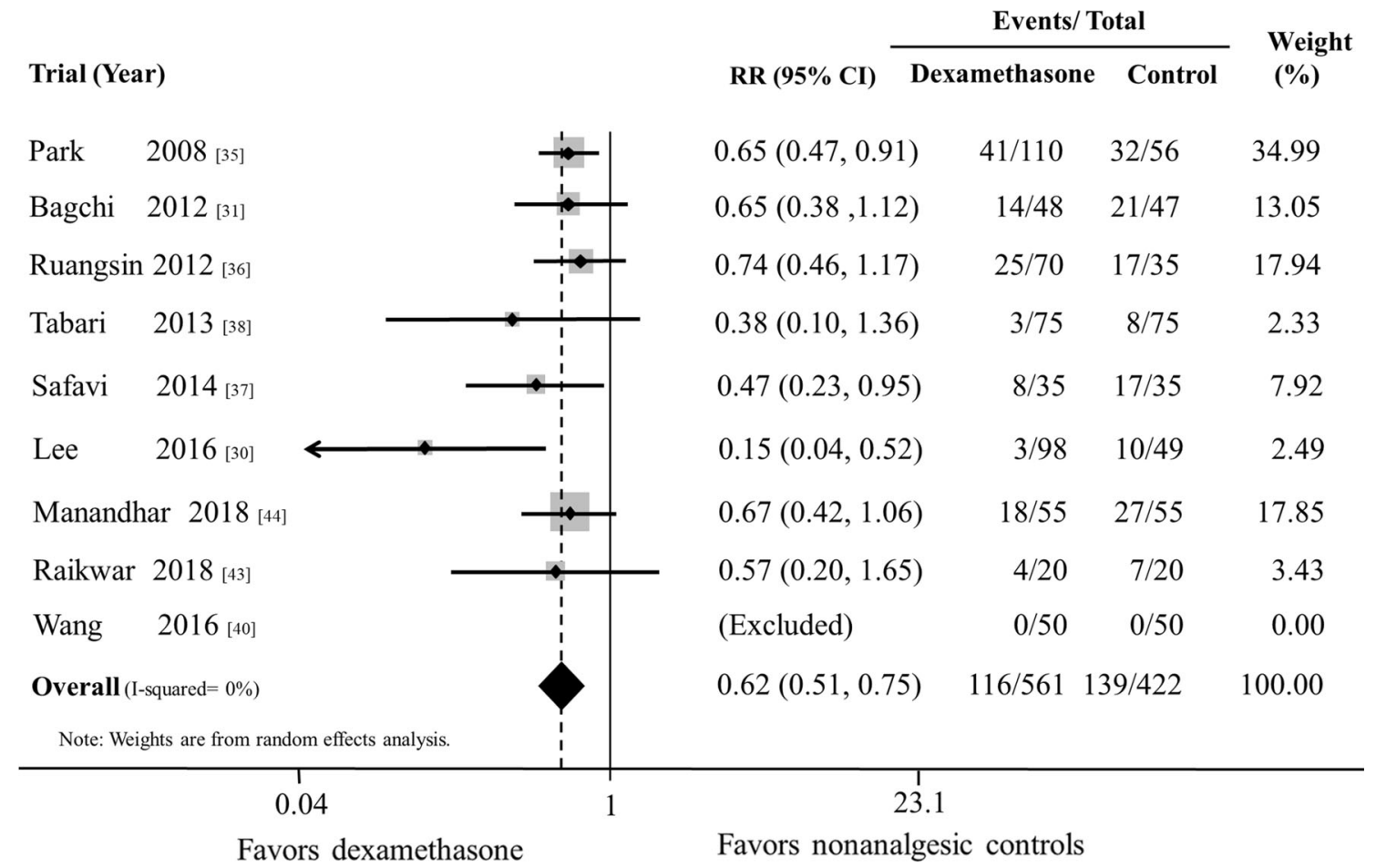

Fig. 2 Forest plot for the incidence of postoperative sore throat at $24 \mathrm{hr}$ after surgery/extubation. The plot shows decreased incidence in patients treated with iv dexamethasone compared with non-analgesic control. $\mathrm{RR}=$ risk ratio

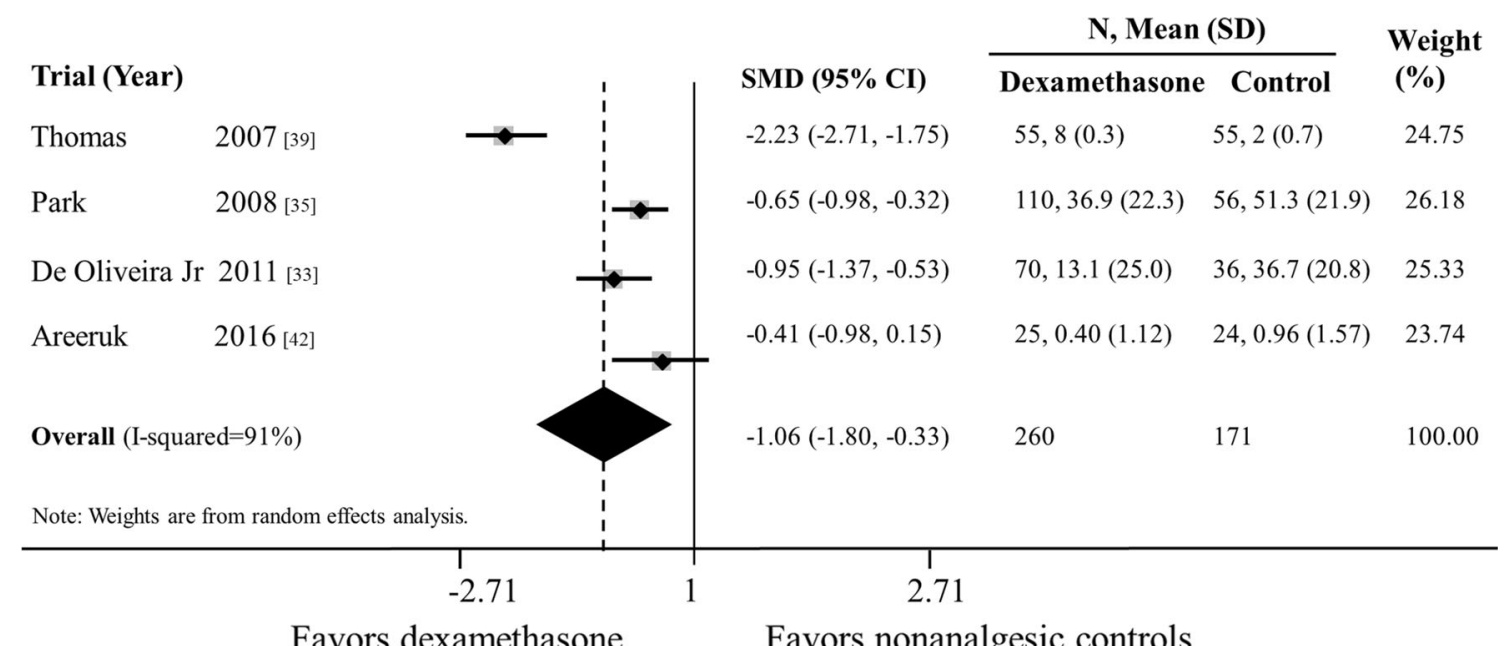

Fig. 3 Forest plot for the severity of postoperative sore throat at $24 \mathrm{hr}$ after surgery/extubation. The plot shows decreased severity in patients treated with $i v$ dexamethasone compared with non-analgesic controls. SD = standard deviation; SMD = standardized mean difference

of postoperative cough $(\mathrm{RR}, 0.66 ; 95 \% \mathrm{CI}, 0.55$ to $0.80 ; P$ $<0.001 ;$ df $=2 ; I^{2}=0 \%$; Fig. 5).

\section{Postoperative hoarseness}

Six studies including 621 participants provided information on the incidence of hoarseness at $24 \mathrm{hr}$ after surgery/ extubation. $^{30,31,33,35,37,43}$ Intravenous administration of dexamethasone was associated with a reduced incidence of postoperative hoarseness (RR, $0.47 ; 95 \% \mathrm{CI}, 0.31$ to $0.74 ; P=0.001$; df $=5 ; I^{2}=61.0 \%$; Fig. 6). 
Trial (Year)

$\begin{array}{ll}\text { Bagchi } & 2012^{[31]} \\ \text { Ruangsin } & 2012[36] \\ \text { Lee } & 2016[30] \\ \text { Manandhar } & 2018[44] \\ \text { Raikwar } & 2018[43] \\ \text { Wang } & 2016_{[40]}\end{array}$

Overall (I-squared $=0 \%)$

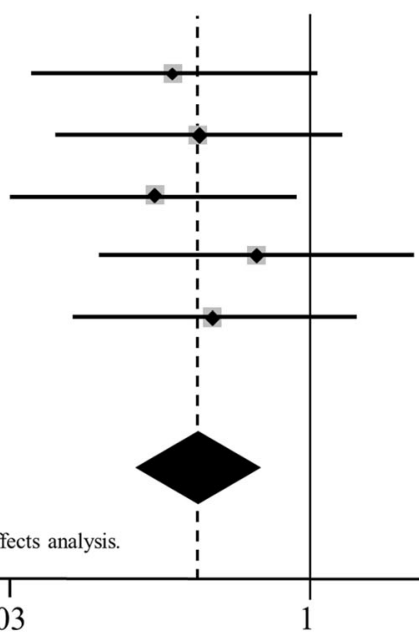

Favors nonanalgesic controls

Fig. 4 Forest plot for the incidence of moderate or severe postoperative sore throat at $24 \mathrm{hr}$ after surgery/extubation. The plot shows decreased incidence in patients treated with $i v$ dexamethasone compared with non-analgesic controls. $\mathrm{RR}=$ risk ratio

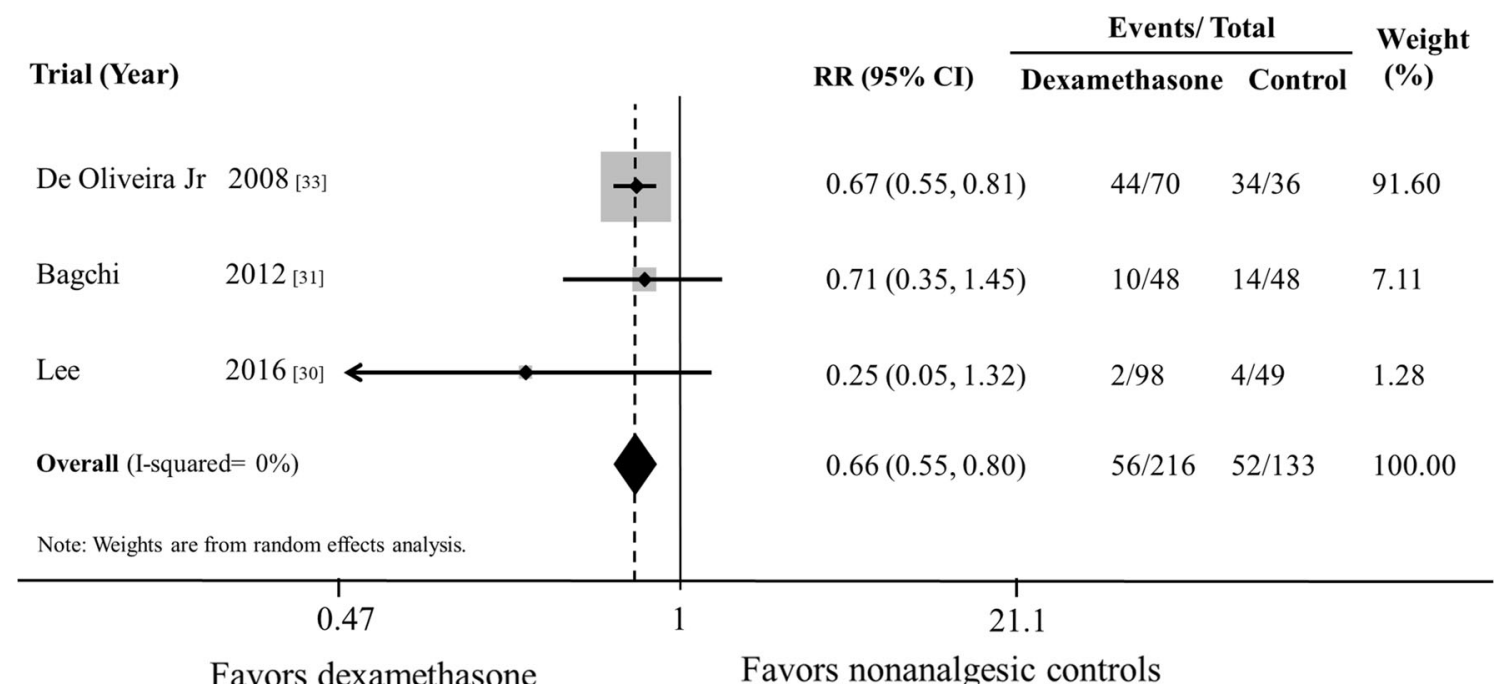

Fig. 5 Forest plot for the incidence of postoperative cough at $24 \mathrm{hr}$ after surgery/extubation. The plot shows decreased incidence in patients treated with $i v$ dexamethasone compared with non-analgesic controls. $\mathrm{RR}=$ risk ratio

\section{Subgroup, sensitivity, and trial sequential analyses}

There was no significant difference in the incidence of postoperative sore throat between subgroups created according to the type of comparator $(P=0.46$; eTable, available as Electronic Supplementary Material). The results of sensitivity analyses excluding studies at an unclear or high risk of bias were consistent with those of primary analyses for all outcomes (eTable, available as
Electronic Supplementary Material [ESM]). Trial sequential analysis suggested that the cumulative $\mathrm{z}$ curve crossed both the conventional and trial sequential monitoring boundaries for benefit before reaching the required information size (2,020 participants), which therefore supports the true positive efficacy of intravenous dexamethasone for preventing postoperative sore throat (Fig. 7). 
Trial (Year)

Park $2008[35]$

De Oliveira Jr $2011[33]$

Bagchi 2012

Safavi $2014[37]$

Lee $\quad 2016[30]$

Raikwar $2018_{[43]}$

Overall $(\mathrm{I}$-squared $=61 \%)$

Note: Weights are from random effects analysis

0.57

Favors dexamethasone
Events/ Total

RR (95\% CI) Dexamethasone Control (\%)

$0.51(0.32,0.80) \quad 25 / 110 \quad 25 / 56 \quad 22.93$

$\begin{array}{llll}0.66(0.44,0.99) & 27 / 70 & 21 / 36 & 24.08\end{array}$

$\begin{array}{llll}0.91(0.50,1.68) & 14 / 48 & 15 / 47 & 19.18\end{array}$

$0.31(0.11,0.85) \quad 4 / 35 \quad 13 / 35 \quad 11.54$

$\begin{array}{llll}0.15(0.06,0.38) & 5 / 98 & 16 / 46 & 12.68\end{array}$

$\begin{array}{llll}0.38(0.12,1.21) & 3 / 20 & 8 / 20 & 9.59\end{array}$

$\begin{array}{llll}0.47(0.31,0.74) & 78 / 381 & 98 / 240 & 100.00\end{array}$

Fig. 6 Forest plot for the incidence of postoperative hoarseness at $24 \mathrm{hr}$ after surgery/extubation. The plot shows decreased incidence in patients treated with $i v$ dexamethasone compared with non-analgesic controls. $\mathrm{RR}=$ risk ratio

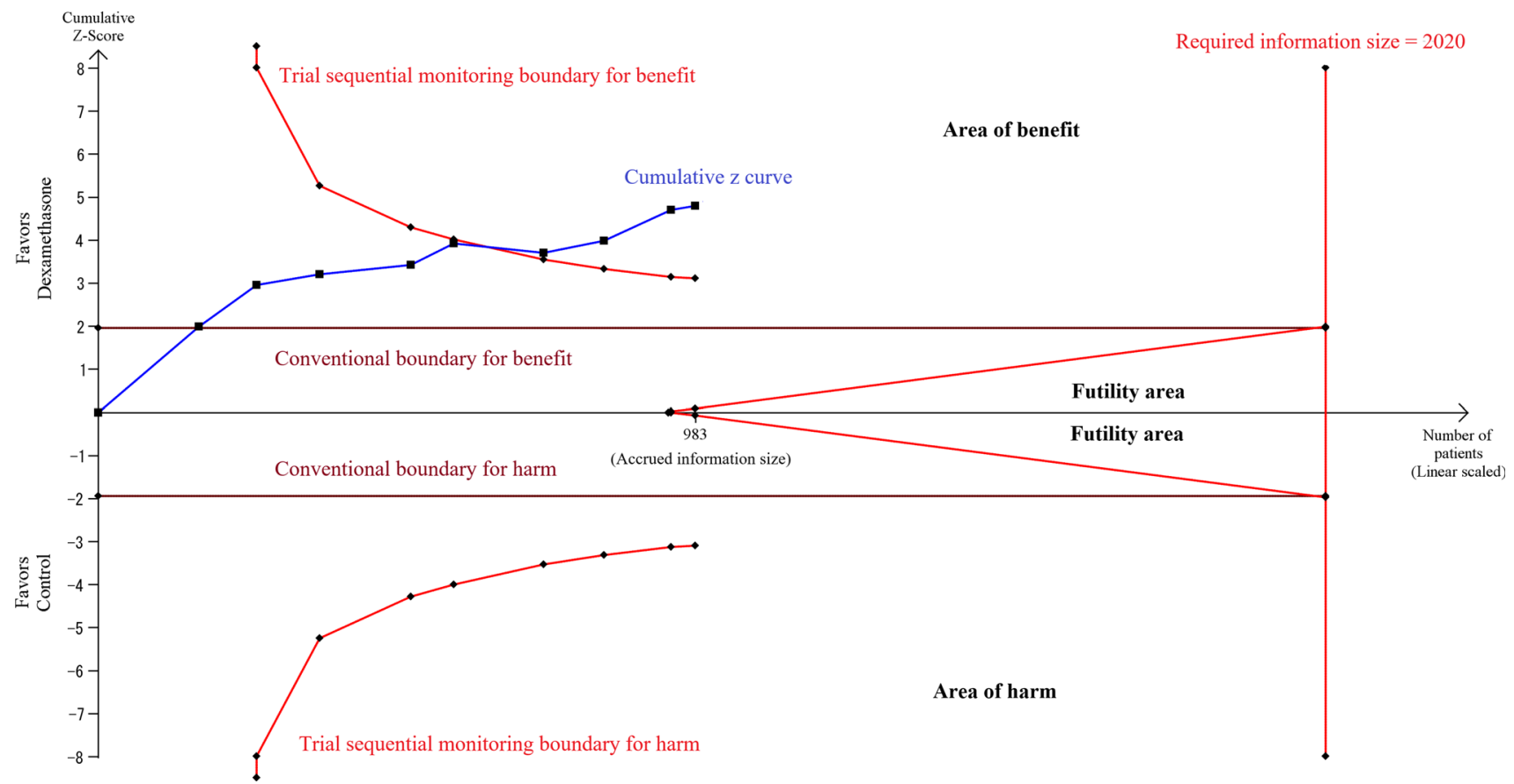

Fig. 7 Trial sequential analysis for the incidence of postoperative sore throat at $24 \mathrm{hr}$ after surgery/extubation in patients treated with $i v$ dexamethasone or non-analgesic controls. The cumulative $\mathrm{z}$ curve (blue line) crosses the conventional boundary for benefit ( $\mathrm{z}$ score of 1.96; horizontal brown line) and the trial sequential monitoring boundary for benefit (red line), demonstrating true positive evidence to suggest that no further studies are required. A diversity-adjusted required information size of 2,020 patients (red vertical line) was calculated, using $\alpha=0.05$ (two-sided) and $\beta=0.20$ (power of $80 \%$ ) and an anticipated relative risk reduction of $20 \%$ 
We examined the relationship between the effect size (incidence of sore throat) and dexamethasone dose. Subgroup analysis found a similar effect size between groups that reported the dexamethasone dose $(P=0.61)$ : low dose (RR, $0.62 ; 95 \% \mathrm{CI}, 0.35$ to $1.09 ; \mathrm{df}=2 ; I^{2}=42 \%$ ) and intermediate dose (RR, 0.60; $95 \%$ CI, 0.47 to 0.76 ; df $\left.=6 ; I^{2}=0 \%\right)$. Meta-regression $(P=0.19)$ failed to find a dose-response relationship (eFigure, available as ESM).

\section{Dexamethasone vs active controls}

Five trials employed analgesic agents as comparators. $^{32,34,37,38,41}$ The comparators were corticosteroids applied to endotracheal tube cuffs in two trials, ${ }^{38,41}$ ketamine gargles and intravenous dexamethasone in two trials, ${ }^{37,43}$ ketamine gargles ${ }^{37,43}$ in two trials, intravenous dexamethasone and intravenous lidocaine in one trial, ${ }^{32}$ and intravenous dexamethasone and acetaminophen in one trial. ${ }^{34}$

With regard to the prevention of postoperative sore throat, intravenous dexamethasone administration was similar to corticosteroids applied to endotracheal tube cuffs $^{38,41}$ or ketamine gargles alone (RR, 0.80; 95\% CI, 0.41 to 1.52$),{ }^{37,43}$ or intravenous dexamethasone and acetaminophen, ${ }^{34}$ while it was inferior to ketamine gargles and intravenous dexamethasone (RR, 2.25; 95\% CI, 1.13 to 4.48$)^{37,43}$ or intravenous dexamethasone and intravenous lidocaine. ${ }^{32}$ With regard to the prevention of postoperative hoarseness, intravenous dexamethasone was similar to ketamine gargles and intravenous dexamethasone (RR, 1.17; 95\% CI, 0.42 to 3.26$),{ }^{37,43}$ ketamine gargles alone (RR, 0.70; 95\% CI, 0.29 to 1.71), ${ }^{37,43}$ intravenous dexamethasone and intravenous lidocaine, ${ }^{32}$ or intravenous dexamethasone and acetaminophen. ${ }^{34}$

\section{Discussion}

Our review suggests that, compared with non-analgesic controls, preoperative intravenous administration of dexamethasone was associated with a reduced incidence and severity of postoperative sore throat in adults undergoing elective surgery under anesthesia/endotracheal intubation. Our analysis indicates that the number of patients needed to treat with intravenous dexamethasone (to prevent one case of postoperative sore throat) is eight (95\% CI, 5 to 20), which indicates a considerable prophylactic benefit. Intravenous dexamethasone administration also decreased the incidence of moderate or severe sore throat as well as hoarseness and cough after surgery. Limited available evidence suggests that intravenous dexamethasone administration is not associated with significant adverse events. Our findings were robust throughout the sensitivity analysis and TSA, providing strong evidence that preoperative intravenous dexamethasone administration effectively alleviates postoperative sore throat.

The presumed etiology underlying postoperative sore throat is mucosal inflammation around the tracheal tube cuff. $^{12}$ Previous studies suggest that topical and intravenous anti-inflammatory agents prevent postoperative sore throat in surgical patients, ${ }^{16-18,45}$ thus supporting this explanation. Furthermore, intravenous corticosteroids administered to critical care patients prior to elective extubation decrease laryngeal edema and reduce post-extubation airway complications. ${ }^{46}$ In line with this evidence, our study suggests that preoperative intravenous dexamethasone administration is associated with a reduced risk of postoperative sore throat.

Some studies have attempted to examine a doseresponse relationship by testing two doses of dexamethasone. Our subgroup and meta-regression analyses suggest no association between the dose of dexamethasone and the effect size. We assumed a mean body weight of $60 \mathrm{~kg}$ because most studies were conducted outside North America. Re-analysis with an assumed body weight of $70 \mathrm{~kg}$ yielded similar findings. Although our findings do not elucidate the optimal dexamethasone dose for preventing postoperative sore throat, we believe that low-dose dexamethasone may be effective.

Previous studies have suggested that topical application of ketamine and corticosteroids help to prevent postoperative sore throat. ${ }^{17,47}$ Our study suggests that intravenous dexamethasone is superior to topical ketamine, while topical corticosteroids and most analgesic agents combined with intravenous dexamethasone are no better than intravenous dexamethasone alone. Nevertheless, most of these comparisons were performed in single, small-sized trials and we believe that additional studies of this nature are warranted.

Our review could not adequately assess adverse events associated with intravenous dexamethasone. In 1996, The Consolidated Standards of Reporting Trials (CONSORT) statement recommended that trial investigators should report unintended effects related to interventions. ${ }^{48}$ All studies that are included in our review were published after this statement. Nevertheless, only four studies reported adverse events and few details were provided. There is literature indicating that short-term, high-dose corticosteroids and single-dose intravenous dexamethasone are not associated with significant adverse events. ${ }^{27,46}$ By analogy, we speculate that the prophylactic intravenous administration of dexamethasone to prevent sore throat is unlikely to be related to significant adverse events. 
Two previous systematic reviews suggested that intravenous administration of dexamethasone helps to prevent postoperative sore throat. ${ }^{19,20}$ Our findings are in agreement with these studies. Nevertheless, there are substantial differences between those reviews and the present one. First, the previous reviews included four and seven trials, respectively, whereas this report includes 15 studies, 13 of which included non-analgesic controls. Second, we pooled efficacy outcomes strictly at $24 \mathrm{hr}$ after surgery/extubation. In contrast, the previous reviews pooled outcomes recorded over a wide range of time intervals because the original studies were few and inconsistent in reporting their outcomes; we excluded two such trials, which were included in the previous reviews. Third, we included two non-English language reports and studies involving comparisons with other analgesic agents; thus, our review was more comprehensive. Fourth, our TSA suggested true positive efficacy of intravenous dexamethasone administration to help prevent postoperative sore throat.

Additional strengths of our study include the comprehensive nature of the literature search, which identified 15 publications thus permitting sensitivity and meta-regression analyses. Moreover, we compared intravenous dexamethasone with topical corticosteroids and ketamine, which are known prophylactic measures to prevent postoperative sore throat. Finally, we complied with the Cochrane methodology. We contacted the original study authors to more accurately evaluate the risk of bias and requested necessary unpublished data. We also confirmed the robustness of our findings with sensitivity analysis and TSA.

Nevertheless, our review is not without limitations. First, the number of pooled studies for each outcome was relatively small even though the TSA provided strong evidence for the efficacy of preoperative intravenous dexamethasone. Second, there is a possibility of publication bias for each outcome. We were unable to test for publication bias given the limited number of studies available for each outcome, according to the recommendation of the Cochrane Collaboration. Third, there were potentially diverse, un-controlled confounding variables of the included trials. For example, operator inexperience, elevated cuff pressure, larger tracheal tubes, and a prolonged duration of intubation are known risk factors for postoperative sore throat. Unfortunately, we could not adjust for these variables because they were inconsistently reported.

In conclusion, our study suggests that preoperative intravenous dexamethasone administration alleviates postoperative sore throat more effectively than nonanalgesic strategies.
Conflicts of interest None declared.

Editorial responsibility This submission was handled by Dr. Steven Backman, Associate Editor, Canadian Journal of Anesthesia.

Author contributions Akira Kuriyama contributed substantially to all aspects of this manuscript, including study conception and design, acquisition, analysis, and interpretation of data, and drafting the article. Hirokazu Maeda contributed substantially to the acquisition of data, interpretation of data, and drafting the article.

Financial disclosures None.

\section{References}

1. Ahmed A, Abbasi S, Ghafoor HB, Ishaq M. Postoperative sore throat after elective surgical procedures. J Ayub Med Coll Abbottabad 2007; 19: 12-4.

2. Biro P, Seifert B, Pasch T. Complaints of sore throat after tracheal intubation: a prospective evaluation. Eur J Anaesthesiol 2005; 22: 307-11.

3. Christensen AM, Willemoes-Larsen H, Lundby L, Jakobsen KB. Postoperative throat complaints after tracheal intubation. $\mathrm{Br} \mathrm{J}$ Anaesth 1994; 73: 786-7.

4. Higgins PP, Chung F, Mezei G. Postoperative sore throat after ambulatory surgery. Br J Anaesth 2002; 88: 582-4.

5. Maruyama K, Sakai $H$, Miyazawa $H$, et al. Sore throat and hoarseness after total intravenous anaesthesia. Br J Anaesth 2004; 92: 541-3.

6. Sanou J, Ilboudo D, Rouamba A, Traore O. Sore throat after tracheal intubation (French). Cah Anesthesiol 1996; 44: 203-6.

7. Lehmann M, Monte K, Barach P, Kindler $\mathrm{CH}$. Postoperative patient complaints: a prospective interview study of 12,276 patients. J Clin Anesth 2010; 22: 13-21.

8. Inoue $S$, Abe $R$, Tanaka $Y$, Kawaguchi $M$. Tracheal intubation by trainees does not alter the incidence or duration of postoperative sore throat and hoarseness: a teaching hospital-based propensity score analysis. Br J Anaesth 2015; 115: 463-9.

9. Macario A, Weinger M, Carney S, Kim A. Which clinical anesthesia outcomes are important to avoid? The perspective of patients. Anesth Analg 1999; 89: 652-8.

10. Tong D, Chung F, Wong D. Predictive factors in global and anesthesia satisfaction in ambulatory surgical patients. Anesthesiology 1997; 87: 856-64.

11. Chandler $M$. Tracheal intubation and sore throat: a mechanical explanation. Anaesthesia 2002; 57: 155-61.

12. Combes $X$, Schauvliege $F$, Peyrouset $O$, et al. Intracuff pressure and tracheal morbidity: influence of filling with saline during nitrous oxide anesthesia. Anesthesiology 2001; 95: 1120-4.

13. Donnelly WH. Histopathology of endotracheal intubation. An autopsy study of 99 cases. Arch Pathol 1969; 88: 511-20.

14. Loeser EA, Hodges M, Gliedman J, Stanley TH, Johansen RK, Yonetani D. Tracheal pathology following short-term intubation with low- and high-pressure endotracheal tube cuffs. Anesth Analg 1978; 57: 577-9.

15. Way WL, Sooy FA. Histologic changes produced by endotracheal intubation. Ann Otol Rhinol Laryngol 1965; 74: 799-812.

16. Kuriyama A, Maeda $H$, Sun $R$. Aerosolized corticosteroids to prevent postoperative sore throat in adults: a systematic review and meta-analysis. Acta Anaesthesiol Scand 2018; DOI: https:// doi.org/10.1111/aas.13275. 
17. Kuriyama A, Maeda $H$, Sun $R$, Aga M. Topical application of corticosteroids to tracheal tubes to prevent postoperative sore throat in adults undergoing tracheal intubation: a systematic review and meta-analysis. Anaesthesia 2018; DOI: https://doi. org/10.1111/anae.14273.

18. Kuriyama A, Aga M, Maeda $H$. Topical benzydamine hydrochloride for prevention of postoperative sore throat in adults undergoing tracheal intubation for elective surgery: a systematic review and meta-analysis. Anaesthesia 2018; 73: 889900.

19. Zhao $X$, Cao $X, L i Q$. Dexamethasone for the prevention of postoperative sore throat: a systematic review and meta-analysis. J Clin Anesth 2015; 27: 45-50.

20. Sun L, Guo $R$, Sun L. Dexamethasone for preventing postoperative sore throat: a meta-analysis of randomized controlled trials. Ir J Med Sci 2014; 183: 593-600.

21. Higgins JP, Green S. Cochrane Handbook for Systematic Reviews of Interventions. England: John Wiley \& Sons, Ltd; 2008 .

22. Moher D, Liberati A, Tetzlaff J, Altman DG; PRISMA Group. Preferred reporting items for systematic reviews and metaanalyses: the PRISMA statement. BMJ 2009; 339: b2535.

23. Sweeting MJ, Sutton AJ, Lambert PC. What to add to nothing? Use and avoidance of continuity corrections in meta-analysis of sparse data. Stat Med 2004; 23: 1351-75.

24. Wan X, Wang W, Liu J, Tong T. Estimating the sample mean and standard deviation from the sample size, median, range and/or interquartile range. BMC Med Res Methodol 2014; 14: 135.

25. DerSimonian R, Laird $N$. Meta-analysis in clinical trials. Control Clin Trials 1986; 7: 177-88.

26. Higgins JP, Thompson SG, Deeks JJ, Altman DG. Measuring inconsistency in meta-analyses. BMJ 2003; 327: 557-60.

27. De Oliveira GS, Jr Almeida MD, Benzon HT, McCarthy RJ. Perioperative single dose systemic dexamethasone for postoperative pain: a meta-analysis of randomized controlled trials. Anesthesiology 2011; 115: 575-88.

28. Wetterslev J, Jakobsen JC, Gluud C. Trial Sequential Analysis in systematic reviews with meta-analysis. BMC Med Res Methodol 2017; 17: 39.

29. Jackson JL, Kuriyama A. From the Editors' desk: bias in systematic reviews-let the reader beware. J Gen Intern Med 2018; 33: $133-5$.

30. Lee SH, Lee YC, Lee JH, et al. The prophylactic effect of dexamethasone on postoperative sore throat in prone position surgery. Korean J Anesthesiol 2016; 69: 255-61.

31. Bagchi D, Mandal MC, Das S, Sahoo T, Basu SR, Sarkar S. Efficacy of intravenous dexamethasone to reduce incidence of postoperative sore throat: a prospective randomized controlled trial. J Anaesthesiol Clin Pharmacol 2012; 28: 477-80.

32. Cho CK, Kim JE, Yang HJ, Sung TY, Kwon HU, Kang PS. The effect of combining lidocaine with dexamethasone for attenuating postoperative sore throat, cough, and hoarseness. Anesth Pain Med 2016; 11: 42-8.

33. De Oliveira GS, Jr Ahmad S, Fitzgerald PC, et al. Dose ranging study on the effect of preoperative dexamethasone on postoperative quality of recovery and opioid consumption after ambulatory gynaecological surgery. Br J Anaesth 2011; 107: 36271.

34. Lee J, Park HP, Jeong MH, Kim HC. Combined intraoperative paracetamol and preoperative dexamethasone reduces postoperative sore throat: a prospective randomized study. J Anesth 2017; 31: 869-77.
35. Park SH, Han SH, Do SH, Kim JW, Rhee KY, Kim JH. Prophylactic dexamethasone decreases the incidence of sore throat and hoarseness after tracheal extubation with a doublelumen endobronchial tube. Anesth Analg 2008; 107: 1814-8.

36. Ruangsin S, Wanasuwannakul T, Pattaravit $N$, Asim $W$. Effectiveness of a preoperative single dose intravenous dexamethasone in reducing the prevalence of postoperative sore throat after endotracheal intubation. J Med Assoc Thai 2012; 95: 657-60.

37. Safavi M, Honarmand A, Fariborzifar A, Attari M. Intravenous dexamethasone versus ketamine gargle versus intravenous dexamethasone combined with ketamine gargle for evaluation of post-operative sore throat and hoarseness: a randomized, placebo-controlled, double blind clinical trial. Adv Biomed Res 2014; 3: 212.

38. Tabari $M$, Soltani $G$, Zirak $N$, Alipour $M$, Khazaeni $K$. Comparison of effectiveness of betamethasone gel applied to the tracheal tube and iv dexamethasone on postoperative sore throat: a randomized controlled trial. Iran J Otorhinolaryngol 2013; 25: 215-20.

39. Thomas S, Beevi $S$. Dexamethasone reduces the severity of postoperative sore throat. Can J Anesth 2007; 54: 897-901.

40. Wang $Y, L i G, D u Q$. Application of dexamethasone in the treatment of airway complications after laparoscopic complications after laparoscopic cholecystectomy (Chinese). Chinese Community Doctors 2016; 32: 24-5.

41. Wijaya AA, Garditya $R$, Marsaban AH, Heriwardito A. Perbandingan penggunaan triamsinolon asetonid topikal dengan deksametason intravena dalam mengurangi insidens nyeri tenggorok pascabedah (Indonesian). Jurnal Anestesi Perioperatif 2015; 3: 117-22.

42. Areeruk $P$, Ittichaikulthol $W$, Termpornlert $S$, et al. $T$ he effect of a single dose dexamethasone on postoperative pain in patients undergoing gynecological laparotomy surgery. J Med Assoc Thai 2016; 99: 1239-44.

43. Raikwar SK, Ahirwal R, Sweety B. Comparative study between intravenous dexamethasone versus ketamine gargle versus intravenous dexamethasone combined with ketamine gargle for evaluation of post-operative sore throat and hoarseness in middle ear surgery. J Evol Med Dent Sci 2018; 7: 1639-43.

44. Manandhar S, Manandhar K, Khakrel S. Efficacy of dexamethasone in reducing the incidence of postoperative sore throat: a double blind randomized study. J Patan Acad Health Sci 2018; 5: 10-5.

45. Ruetzler $K$, Fleck $M$, Nabecker $S$, et al. A randomized, doubleblind comparison of licorice versus sugar-water gargle for prevention of postoperative sore throat and postextubation coughing. Anesth Analg 2013; 117: 614-21.

46. Kuriyama A, Umakoshi N, Sun R. Prophylactic corticosteroids for prevention of postextubation stridor and reintubation in adults: a systematic review and meta-analysis. Chest 2017; 151: 1002-10.

47. Mayhood J, Cress K. Effectiveness of ketamine gargle in reducing postoperative sore throat in patients undergoing airway instrumentation: a systematic review. JBI Database System Rev Implement Rep 2015; 13: 244-78.

48. Begg C, Cho M, Eastwood $S$, et al. Improving the quality of reporting of randomized controlled trials. The CONSORT statement. JAMA 1996; 276: 637-9.

Publisher's Note Springer Nature remains neutral with regard to jurisdictional claims in published maps and institutional affiliations. 